\title{
MEASURING SOCIO-ECONOMIC PROGRESS IN INDIA: ISSUES AND CHALLENGES
}

Deepak Kumar Behera

Assistant Professor, Department of Humanities and Social Sciences, National Institute of Technology Patna (An Institute under MHRD, Govt. of India), Ashok Rajpath, Patna,, Bihar800 005, India, E-mail: dkb@nitp.ac.in, dkbehera1982@gmail.com

Abstract: One of the challenges to the National Statistical Systems worldwide is to capture
the indicators of socio-economic progress from the current available framework. The limits
of traditional indicators provide little insights about the extent of well being realised in the
society, since there is no automatic link between growth and development which aims at
improving human and social welfare. Therefore, different countries had tried various
approaches to measure their progress of the society. India's experience with measuring
progress in the society ranges from computation of composite index to adoption of a
development strategy that emphasises human welfare and well-being of the society as
central to all development planning. In this connection, this paper limits its scope to some of
the challenges and possibilities in the Indian system for developing the indicators of social
progress.
Keywords: , Statistics, Socio-economic progress, Growth and Development

\section{Introduction}

Enhancement of human welfare is the most important function of a modern welfare government and for performing this function; it is required to make policies for the masses. However, for measuring the progress made in enhancing development in the economy, specific indicators are required. Whether these indicators truly reflect the real economic scenario is a matter to be further analyzed. Traditionally, nations have been using the GDP, GNP and its components as a proxy for measuring the development in an economy. However, economic literature reveals the limitations of these indicators as a real measure of development. Human welfare has wider dimensions of equity, capabilities, basic needs, sustainability etc. which necessitate the need of broad indicators which measure the development on wider perspectives. Modern welfare states have been devising new policies ensuring universal primary education, clean and safe drinking water, access to health benefits, hygiene and proper living conditions. These measures and many more help raise the standards of living of societies and the performance of the Governments is assessed based on these standards itself. Certain new indicators of development have been in vogue namely Human Development Index (HDI) ${ }^{1}$, Millennium Development Goals (MDG) ${ }^{2}$, Multidimensional Poverty Index (MPI) ${ }^{3}$, etc. which have made their respective contributions in assessing the human development, though with their own limitations.

In spite of usage of all these indicators, there is still a need for devising a common multidimensional indicator to assess the success of government policies and the progress

1 Human Development Index (HDI) combines GDP with health and education indicators. (See. http:/ / unpan1.un.org/intradoc/ groups/ public/ documents/ un/ unpan004152.pdf)

2 MDG considered as another step forward in the process. MDGs set a combination of quantitative and qualitative targets to be achieved in a time bound framework. However, one of the limitations of MDG remains in the fact that it could not be strictly measured in country specific statistical system along with existing data gap, which makes the comparison difficult. (See http:// www.unescap.org/pdd/ CPR/ CPR2006/ English/ CPR3 3E.pdf)

3 The very recent Multidimensional Poverty Index developed under Oxford initiative takes cognizance of various deprivations in a society that an individual faces. 
of societies at large. The major limitation of all the existing indicators is that these indicators do not measure the extent of deprivation prevalent in the societies which is the basis for formulating the developmental policies ahead. Thus the task which lies ahead involves

1. Designing such indicators of progress which truly reflect the real development scenario of the economy.

2. Evolving effective methodologies for strengthening of the national database through suitable statistical systems ensuring capturing of vital information on measuring the extent of deprivation.

3. Deriving suitable instruments to get a combined effect of objective and subjective criterias of measuring progress.

India being no exception to this, is striving for evolving a statistical system that meets the above challenges. It is committed to the global initiatives on developing and harmonizing the statistical system in line with international conventions such as UNSNA, MDG, HISCode classification for trade statistics. India's inclusive growth model adopted as a development strategy in the Eleventh and Twelfth Five Year Plan emphasized the policy framework that broadly converges with social welfare approach of development. At the same time, setting up a permanent National Statistical Commission and setting up of statistical units in all the central ministries and departments are some initiatives towards strengthening of statistical administration.

This paper limits its scope to some of the challenges and possibilities in the Indian system for developing the indicators of social progress. In this connection, the present article provides the understanding of broad agreements on indicators to measure social progress in one hand and highlights some of the pertinent issues in Indian statistical system and assessing the possibilities of finding development indicators to begin with from current system on the other.

\section{Limitations of present indicators of measurement}

There is ample evidence in the literature well diversified yet with a strong convergence on the importance and need for developing measures for social progress other than indicators like GDP. Before we embark upon the discussion of various approaches to measure social progress in a country, it is essential to understand why GDP lacks in measuring the well being of a society.

GDP- The current measurement of GDP measures the monetary value of all final goods and services that are produced by various agents of society. The use of real GDP allows us to adjust the changes that are made in the GDP valuation, neutralizing the inflation effects that might have occurred over a period of time. However here have been certain serious considerations while relying on GDP estimates as a basis of true measure of welfare in society. Firstly, the GDP accounting does not take into account the non monetary segment of society. e.g. provision of free medical insurance. The valuation of market price of such commodity may not reflect the true picture of how society values this commodity. The market prices of certain commodities do not reflect the real externalities/ costs involved in their usage. Also the current GDP estimates measure only the quantitative changes in the value of goods and services. They do not take into account the value of qualitative changes made in the consumption baskets, if any.

Besides, there are number of well established limitations of GDP as a development index which are recapitulated in brief. 
- GNP measures only flows, ignores value of people's existing possession( except for imputed rent of housing)

- It ignores depreciation of environmental wealth and human capital caused by unhealthy working condition. "Many aspects of quality of life and the environment fall outside the market calculus" (Baster, 1972, p.3).

- Other sources of welfare like leisure time, quality of life at work etc. are not absorbed in GNP estimate.

- Being an average, per-capita GNP makes no allowance for changing income distribution. At a given level of GNP, the pattern of consumption may be markedly changed by altering income distribution having implication for social welfare.

- GNP is a highly value loaded indicator, with increasing subjectivity for countries with poorer statistics and larger subsistence sector than for countries where a much smaller proportion of transactions bypass the market., since every type of product and services is assigned its own particular weight (many being zero).

- Wide prevalence of market imperfection and policy induced administered price, make the prices used for valuing components of GNP differ from appropriate social valuation.

- Present income level provides little guidance to future growth process, by underscoring the investment in human capital.

- Omission of a high proportion of household services (no data is available even for those which are remunerated) and inadequate allowance for the consumption of nontraded goods and services underestimates GDP for poorer countries.

- Inappropriateness of exchange rate to convert GNP to international currency units (US dollar) makes international comparison inappropriate.

- Implicit treatment of costs (like cost of travelling to work) as benefit in the GNP estimation distorts measure of welfare.

Perception of economic development as described above poses a number of conceptual and statistical limitation on the GNP per capita as an index. Concern about the limitations of GNP per capita as an inappropriate index of development has led to experimentation in other direction. Important among the alternative approaches are (i) adjustment to GNP, (ii) defining non-monetary measures of social progress and (iii) development of composite index.

Adjustments to GNP- Some adjustments to GDP have been suggested by Hicks and Streeten (1979) namely (i) Conversion of national accounting using the purchasing power (ii) reducing certain unavoidable non developmental necessities and adding certain values of leisure and service (iii) assigning more weights to poverty (iv) estimation of monetary equivalents of certain environmental hazards (v) incorporation of some social indicators into GNP etc. Stiglitz, Sen and Fitoussi (2009) have articulated some additional adjustment to GNP for capturing the social welfare aspect of economic achievement. These are (a) calculating imputed values for certain goods and services consumed, (b) using a stock concept for estimating the available capital in the country, (c) estimation of monetary equivalent of environmental damage in national accounts; depletion of natural resources while estimating total depreciation etc. However, these adjustments have their own limitations in making intra household comparison difficult and complexities of involving subjective values into assessment. 
Non Monetary indicators- Non monetary indicators of development are theoretical more ideal as they avoid the differences in exchange rate values and valuations. They incorporate capturing and use of unemployment scenario, inequalities of income, literacy, life expectancy, etc. However these measures cannot be free from limitations namely definitional differences in unemployment and poverty, limited data collected on sample survey and absence of any common denominator for combining these values. Also some of these measures find limited applicability since they assume maximum values of human capabilities namely 100 for literacy and 85 for life expectancy, which is very vague.

\section{Human Development Index (HDI): The Composite Index}

Attempts have been made to develop single index combining social, economic, political indicators based on different development paradigm. The latest and most comprehensive exercise is by UNDP to compute HDI by combining three dimensions such as decent standard of living, knowledge and long and healthy life each with equal weight. Indicators under these three dimensions are still evolving the latest (HDR-2010) set of measurable indicators being per-capita GNI, mean year of schooling and expected year of schooling, and life expectancy at birth. Even the methodology for combing the component indices has undergone change from arithmetic mean to geometric mean.

The problems with composite index are:

- Little theoretical guidance exists to govern the choice of component indices, which are not exhaustive.

- Scaling problems of component indices when raw data on social indicators are converted into component indices ranging from 0-100.

- Use of appropriate weights for combining the component indices to composite one (Equal weights to literacy, Life Expectancy at Birth, implies acceptance of trade-off between the two).

- Index that relies on ranking neglects the distance between ranks.

- All three are averages and conceal the wide disparities within the countries, across region and between various social groups.

\section{Quality of Life:}

The issue of measuring social progress involves understanding of factors that make the life worth living. It may be argued that the subjective well being is an individual's perception and may not be an easy task to be generalized for the society at large. The question so arises what is quality of life then?

There have been different interpretations of quality of life in economic literature. The views range from considering quality of life as a function of religion and philosophy, provision of social and economic justice, freedom of choice (. Rawls, 1971) and Sen's (1989) well known notion of capabilities. Report of the Commission on Measurement of Economic Performance and Social Progress, an approach based on notion of fair allocations, attempts to capture and weighs the non monetary dimensions of life over time irrespective of the preferences based on 'average' willingness to pay principle.

\section{Subjective v/ s Objective Indicators of Life:}

The two approaches of subjective well being and objective factors as measures of quality of life are widely debated upon. Subjective indicators are based on individual's 
experiences from life indicating its satisfactions from life, happiness experienced, perceptions of feelings etc. Here there are chances of flexibility as there is no scope of limitations of statistical data. However the limits of these data lie in its strengths itself. An individual's perceptions of happiness and feelings of life do not necessarily reflect the feelings of society at large in the same way. It makes inter comparisons among countries difficult. However in spite of the limitations, it can be helpful in gaining insight in incorporating certain critical issues such as environmental hazards, ecological damage and unemployment pressures.

The advantages of objective indicators lies in that they are quantitative in nature and hence can be computed statistically using the sample survey, ease in making inter country comparisons, can be defined easily etc. However, their disadvantages lie in that they underreport on certain issues such as crime, domestic violence etc. Also benchmarking of these indicators ignores the critical factors such as cultural differences, political climates, social issues etc.

The best indicator may be considered the one which incorporates advantages of both subjective and objective factors. Some of the indicators incorporating all these factors are recently in use namely HDI, Gross National Happiness, Multi dimensional Poverty Index, Index of Economic Well Being, Weighted Index of Social Progress etc. Vast economic literature available on the topic has converged on having the following components as the basis of these measures of well being:

$\checkmark$ State of economy- it may include cost of living conditions, GDP, GNP, inflation rate etc.

$\checkmark$ Education Status- enrolment ratios, dropout rates, literacy rate etc

$\checkmark$ Health Status- infant mortality rate, maternal mortality rate, life expectancy ratio

$\checkmark$ Infrastructure- tele density, electrification, road density etc.

$\checkmark$ Freedom -economic, political, social and cultural

$\checkmark$ Environment- it includes climatic factors as well

$\checkmark$ Security- economic, social and psychological

Some of these dimensions have cross linkages while some have mutually exclusive outcomes. Nevertheless, it is acceptable to argue that assessing the cross linkages across these dimensions is critical for measuring the extent of inequalities. This also helps developing a framework for aggregating the measures in a synchronised way for policy considerations. One element that needs attention is the fact that measuring quality of life includes a wide range of factors that make life worth living, but are neither traded in markets nor captured by monetary measures alone. Thus while the prevalent economic and statistical system provides a good range of information on some these aspects; it certainly does not cover the exhaustive list of variables required for such assessments. The possible way out in this situation is to include more variables which are subjective in nature (such as environmental factors, recreational facilities, lower crime rate etc.) while collecting the current statistics. If not, separate mechanisms could be designed to obtain information needed to aggregate the quality of life dimensions allowing for construction of different indices.

Within the above mentioned broad groups, enormous possible combinations may exist to measure progress from different perspectives depending on the underlying assumptions of an index. However, the more challenging task is to construct weighting diagram of these indicators. There is no thumb rule to assign weights to these parameters and may produce 
differentiated outcomes depending upon the weights assigned to each variable (Becker, Denby, McGill, and Wilks, 1987). For instance, a country may be performing well on education parameters but lacking in freedom components. As stated earlier, computations of indices on the above dimensions some of which are objective indicators will have a mean or average effect. Thus, the distribution effect may not be assessed in the right way. In addition, the choice of the parameter under each group may depend upon the availability of relevant data.

In sum, developing any index of social progress at national and international level is a complex phenomenon involving components like value judgment, benchmarking of indicators value, and underlying policy considerations etc. Thus, the possibility of biases can not be ruled out completely.

\section{Global Experience on Measuring Progress of the Society}

Over the years, progress has been conventionally and traditionally measured in terms of economic growth with gross domestic product (GDP) and gross national product (GNP) as measures. However, GDP and GNP do not really measure welfare; thus different countries had tried various approaches to measure their progress of the society. Some of the important initiatives are summarized below.

UN Human Development Report, started by UNDP in 1990, measured the computed value of human development on the dimensions of longevity of life, literacy and per capita income. Initially, based on computation of index on simple arithmetic mean, the index now has moved to the geometric mean of the components. The report ranks the countries on the basis of these indexes. The report has made use of new improved indicators such as Gross National Income per capita (PPP US\$), Mean years of Schooling and Expected years of Schooling. Apart from these UNDP has also come up with the gender sensitive measures such as Gender Empowerment Measure for measuring gender differences in all above areas.

Multidimensional Poverty Index-Oxford Poverty and Human Development Initiative (OPHI) of Oxford University and the Human Development Report Office of the United Nations Development Programme (UNDP) have come up with their new MPI. The indicator uses three criteria such as health, education and standard of living. Each dimension and each indicator within the dimension is equally weighted. The dimensions, indicators and deprivation criteria are given below:

1. Health (each indicator weighted equally at $1 / 6$ )

- Child Mortality: If any child has died in the family

- Nutrition: If any adult or child in the family is malnourished

2. Education (each indicator weighted equally at $1 / 6$ )

- Years of Schooling: If no household member has completed 5 years of schooling

- Child Enrolment: If any school-aged child is out of school in years 1 to 8

3. Standard of Living (each of the six indicators weighted equally at 1/18)

- Electricity: If household does not have electricity

- Drinking water: The household does not have access to clean drinking water (according to the MDG guidelines) or clean water is more than 30 minutes walking from home

- Sanitation: The household's sanitation facility is not improved (according to the MDG guidelines), or it is improved but shared with other households

- Flooring: The household has dirt, sand or dung floor 
- Cooking Fuel: The household cooks with dung, wood or charcoal

4. Assets: The household does not own more than one of: radio, TV, telephone, bike, or motorbike, and do not own a car or tractor.

Higher the value of MPI with higher rank implies higher degree of deprivation. The MPI, it is claimed, would provide a multi dimensional picture of people living in hardship to help target resources for amelioration of the living conditions.

Bhutan's Gross National Happiness Index- The concept of Gross National Happiness $(\mathrm{GNH})$, which puts the well-being of individuals at the top of the national development agenda, was first articulated by Bhutanese King Jigme Singye Wangchuck in 1972 but first came to public global attention in 1986. The GNH has nine domains, such as; Psychological Wellbeing (General psychological distress indicators, emotional balance indicators, and spirituality indicators), Time Use (non-work time for happiness and overall quality of life), Community Vitality (family vitality, safety, reciprocity, trust, social support, socialization, and kinship density.), Cultural Diversity and Resilience (Dialect use, traditional sports, community festivals, artisan skill, value transmission, and basic precept), Health (health status, health knowledge and barriers to health), Education (Educational attainment, Dzongkha language, folk, and historical literacy), Ecological Diversity and Resilience (ecological degradation, ecological knowledge, and afforestation), Living Standard (income, housing, food security, and hardship.), and Good Governance (government performance, freedom, and institutional trust). A person who has achieved the cutoff on all these 9 dimensions is considered as happy. The index uses the data collected through a set of questionnaires.

Happy Planet Index- Introduced by New Economic Foundation is an index that combines environmental impact with human well-being to measure the environmental efficiency with which, country by country, people live long and happy lives. It measures the degree to which long and healthy lives are achieved per unit of environmental impact. The index shows the relative efficiency of countries with which they convert the natural resources into long and happy lives for their citizens.

Philippines's Gross National Happiness Index- Progress of the Philippines society is usually measured through the Philippines Gross National Happiness Index (PGNHI) inspired by the GNH of Bhutan. The National Statistical Coordination Board (NSCB) developed a methodology to compute Philippine Happiness Index, which measure the happiness by combining the economic indicators along with some multidimensional measure of the progress. The PGNHI has thus two components: the Philippines Economic Index (PEI) and the Philippines Happiness Index (PHI). The PGNHI is simply the average of the PHI and the PEI.

PHI is a score based survey by subjective indices and includes an initial list of possible domains of happiness that are (a)community participation and volunteer work; (b) cultural activities; (c) education; (d) family; (e) friends; (f) health; ( $g$ ) income and financial security; (h) leisure and sports; (i) love life; (j) religion and/ or spiritual work; (k) sex life; (l) technological know-how; (m) work; (n) economy; (o) environment; (p) government; (q) politics; and (r) others.

The PEI is computed based on the economic performance of the country for the given quarter relative to its performance during the past three quarters. Performance is measured through the quarterly GNP growth rate. For every yes answer to the following seven questions one point is given: (1) is the growth rate acceleration from the previous year? (2) is the growth rate higher than the targeted annual growth rate? (3) is the growth rate higher than in the previous quarter? (4) is the growth rate higher than two quarters 
ago? (5) is the growth rate higher than three quarters ago? (6) is the growth rate higher than the growth rate of Thailand? and (7) is the growth rate higher than the growth rate of Vietnam? The PEI is simply the total number of points divided by seven.

Social Progress Index (SPI) provides a holistic, objective, transparent, outcome-based measure of a country's wellbeing that is independent of economic indicators. The Social Progress Index can be used to compare countries on different facets of social progress, allowing the identification of specific areas of strength or weakness at the country level. It also allows countries to benchmark themselves against peer countries both at the level of individual indicators as well as in terms of more aggregate measures of social progress (Stern et.al, 2015). It aims to capture the level of social development within a given society. It is composed of three overall dimensions: Basic Human Needs (Nutrition and Basic Medical Care, Water and Sanitation, Shelter, Personal Safety), Foundations of Wellbeing (Access to Basic Knowledge, Access to Information and Communications, Health and Wellness, Ecosystem Sustainability), and Opportunity (Personal Rights, Personal Freedom and Choice, Tolerance and Inclusion, Access to Advanced Education). This index allows measurement of each component and each dimension, and yields an overall score and ranking.

\section{Global Project on Measuring the Progress of Societies}

The Global Project on Measuring the Progress of Societies is an international initiative run by the OECD Organisation for Economic Co-operation and Development since 2007 in collaboration with other international and regional partners - to measure, or assess, the progress of societies. The Global Project aims to foster the development of sets of key economic, social, and environmental indicators to provide a comprehensive picture of how the wellbeing of a society is evolving and seeks to encourage each society to consider in an informed way the crucial question: is life getting better? It brings together the large and growing movement that seeks to understand and measure progress. The Global Project is the first systematic global effort to go 'beyond GDP' by enabling and promoting new ways to measure societal progress.

All these global movements that seek to promote more sustainable, equitable, and prosperous societies are reasons for optimism in the collective effort to improve measures of societal progress.

\section{Indian Measures of Social progress-}

One of the challenges to the National Statistical Systems worldwide is to capture the indicators of social progress from the current available framework. This requires collection of new data, improvements in the ongoing exercises through surveys and census, collection of micro-level data, ensuring comparability over time, periodicity and others. However, while considering any changes in the current framework, it involves a firm rationale on the relevance of such modifications given the country specific policy concerns and the costs involved in it. It also needs to address the adaptability and should not be at the expense of losing out vital information collected from earlier system. India has initiated steps in measuring human welfare through a development strategy that ensures human well being and developing a composite index to measure the pace and magnitude of social progress. 


\section{National Human Development Report (NHDR)}

Table 1. Comparative statement between India's HDI and UNDP HDI

\begin{tabular}{|c|c|}
\hline India's HDI & UNDP HDI \\
\hline \multicolumn{2}{|c|}{ Dimensions/ Components } \\
\hline Economic Attainment & Decent Standard of living \\
\hline Educational Attainment & Knowledge \\
\hline Longevity & Long and healthy life \\
\hline \multicolumn{2}{|c|}{ Computational Methodology } \\
\hline Arithmetic mean of three dimensions & Geometric mean of three dimensions \\
\hline / components indices & / components indices. \\
\hline $\mathrm{HDI}_{\mathrm{j}}=1 / 3 * \sum_{\mathrm{i}}\left(\mathrm{X}_{\mathrm{j} j}\right)$ Where $\mathrm{HDI}$ is for the $\mathrm{jth}$ & (The earlier HDI prior to HDR-2010 was \\
\hline State, $\mathrm{X}_{\mathrm{i}}$ reefers to $\mathrm{i}^{\text {th }}$ component indices with $\mathrm{i}$ & computed by arithmetic mean). \\
\hline ranges from 1 to 3 . & $\mathrm{HDI}=\left(\mathrm{X}_{1} \cdot \mathrm{X}_{2} \cdot \mathrm{X}_{3}\right)^{1 / 3}---(\mathrm{i})$ \\
\hline $\mathrm{X}_{\mathrm{ij}}=\left(\mathrm{X}_{\mathrm{ij}}-\mathrm{X}_{\mathrm{i}}^{*}\right) /\left(\mathrm{X}_{\mathrm{ij}}^{* *}-\mathrm{X}_{\mathrm{i}}^{*}\right)---(\mathrm{ii})$ & Where X refers to component indices. \\
\hline $\mathrm{X}_{\mathrm{i}}^{* *}$ and $\mathrm{X}_{\mathrm{i}}^{*}$ are the scaling maximum and minimum & $\mathrm{X}_{\mathrm{ij}}=\left(\mathrm{X}_{\mathrm{ij}}-\mathrm{X}_{\mathrm{i}}^{*}\right) /\left(\mathrm{X}_{\mathrm{ij}}^{* *}-\mathrm{X}_{\mathrm{i}}^{*}\right)--(\mathrm{ii})$ \\
\hline norms. & $\begin{array}{l}\mathrm{X}_{\mathrm{i}}^{* *} \text { and } \mathrm{X}_{\mathrm{i}}^{*} \text { are the scaling maximum and minimum } \\
\text { norms. }\end{array}$ \\
\hline \multicolumn{2}{|c|}{ Component Indices- Economic Attainment } \\
\hline \multirow{2}{*}{$\begin{array}{l}\text { Inflation and Inequality adjusted Monthly Per } \\
\text { Capita Consumption Expenditure (MPCE) }\end{array}$} & Per-capita Gross National Income (GNI) (PPP \$) \\
\hline & - GNI replaces GDP in HDR-2010 \\
\hline \multicolumn{2}{|c|}{ Component Indices- Education/ Knowledge } \\
\hline \multirow{4}{*}{$\begin{array}{l}\text { Intensity of Formal Education (65\% weight) } \\
\text { Literacy Rate for 7+years (35\% weight) }\end{array}$} & Mean Year of Schooling \\
\hline & Expected years of schooling. \\
\hline & There has been an equal weight for both. \\
\hline & $\begin{array}{l}\text { Combination of Gross Enrollment Ratio (GER) } \\
\text { and Adult Literacy rate is replaced with above } \\
\text { two indicators in 2010-HDR }\end{array}$ \\
\hline \multicolumn{2}{|c|}{ Component Indices- Longevity/ Long and Healthy life } \\
\hline $\begin{array}{l}\text { Life Expectancy at age } 1 \text { (65\% weight) } \\
\text { The reciprocal of Infant Mortality rate (35\% } \\
\text { weight). }\end{array}$ & Life Expectancy at Birth \\
\hline
\end{tabular}

Source: Planning Commission, 2011

Moving on the lines of global human development report , India has developed its own National Human Development Report. The NHDR is an attempt to put together development paradigms in the form of development index to measure the amount of social progress made in society. Efforts have also been made to highlight gender gaps and rural urban gaps wherever possible. Some states have also evolved their own State Development Reports. Besides the State specific HDR, the other indices such as Gender Equality Index and Human Poverty Index for each state have been computed. The State specific HDI was computed as a composite index combining three components such as; economic attainment, educational attainment and longevity. Each of these components was assigned equal weight for computation of the HDI as a simple average of the three. Further, Longevity and Educational attainment have sub components, and component index was arrived at by taking weighted average of sub-component indicators. It may be noted that while the three components captured under State specific HDI are similar to those combined under country specific HDI released by UNDP Human Development 
Report, there are some differences between the two in terms of both computation methodology as well as inclusion of component indicators.

\section{India's Inclusive Growth Model}

India has followed the inclusive growth strategy in its Eleventh Five Year Plan (EFP). Subsequently, the Twelfth Five Year Plan seeks to achieve Faster, Sustainable, and More Inclusive Growth. The broad vision of the Twelfth Plan includes several inter-related components: rapid growth that reduces poverty and creates employment opportunities, access to essential services in health and education especially for the poor, equality of opportunity, empowerment through education and skill development, employment opportunities underpinned by the National Rural Employment Guarantee, environmental sustainability, recognition of women's agency and good governance.

Twenty-five core indicators that are listed below reflect the vision of rapid, sustainable and more inclusive growth:

- Economic Growth: 1. Real GDP Growth Rate of 8.0 per cent. 2. Agriculture Growth Rate of 4.0 per cent. 3. Manufacturing Growth Rate of 10.0 per cent. 4. Every State must have an average growth rate in the Twelfth Plan preferably higher than that achieved in the Eleventh Plan.

- Poverty and Employment: 5. Head-count ratio of consumption poverty to be reduced by 10 percentage points over the preceding estimates by the end of Twelfth Five Year Plan. 6. Generate 50 million new work opportunities in the nonfarm sector and provide skill certification to equivalent numbers during the Twelfth Five Year Plan.

- Education: 7. Mean Years of Schooling to increase to seven years by the end of Twelfth Five Year Plan. 8. Enhance access to higher education by creating two million additional seats for each age cohort aligned to the skill needs of the economy. 9. Eliminate gender and social gap in school enrolment (that is, between girls and boys, and between SCs, STs, Muslims and the rest of the population) by the end of Twelfth Five Year Plan.

- Health: 10. Reduce IMR to 25 and MMR to 1 per 1,000 live births, and improve Child Sex Ratio (0-6 years) to 950 by the end of the Twelfth Five Year Plan. 11. Reduce Total Fertility Rate to 2.1 by the end of Twelfth Five Year Plan. 12. Reduce under-nutrition among children aged 0-3 years to half of the NFHS-3 levels by the end of Twelfth Five Year Plan.

- Infrastructure, Including Rural Infrastructure: 13. Increase investment in infrastructure as a percentage of GDP to 9 per cent by the end of Twelfth Five Year Plan. 14. Increase the Gross Irrigated Area from 90 million hectare to 103 million hectare by the end of Twelfth Five Year Plan. 15. Provide electricity to all villages and reduce AT\&C losses to 20 per cent by the end of Twelfth Five Year Plan. 16. Connect all villages with all-weather roads by the end of Twelfth Five Year Plan. 17. Upgrade national and state highways to the minimum two-lane standard by the end of Twelfth Five Year Plan. 18. Complete Eastern and Western Dedicated Freight Corridors by the end of Twelfth Five Year Plan. 19. Increase rural tele-density to 70 per cent by the end of Twelfth Five Year Plan. 20. Ensure 50 per cent of rural population has access to 40 lpcd piped drinking water supply, and 50 per cent gram panchayats achieve Nirmal Gram Status by the end of Twelfth Five Year Plan. 
- Environment and Sustainability: 21. Increase green cover (as measured by satellite imagery) by 1 million hectare every year during the Twelfth Five Year Plan. 22. Add 30,000 MW of renewable energy capacity in the Twelfth Plan. 23. Reduce emission intensity of GDP in line with the target of 20 per cent to 25 per cent reduction over 2005 levels by 2020 .

- Service Delivery: 24. Provide access to banking services to 90 per cent Indian households by the end of Twelfth Five Year Plan. 25. Major subsidies and welfare related beneficiary payments to be shifted to a direct cash transfer by the end of the Twelfth Plan, using the Aadhar platform with linked bank accounts.

\section{India's commitment to MDG}

India has committed itself to achieve the Millennium Development Goals within targeted timeframes and the Ministry of Statistics and Programme Implementation (mospi) is responsible for tracking and monitoring the progress made under the MDGs. For this certain changes have been made in the indicators of the current system. In respect of statistics for tracking these indicators, there are four categories of indicators:

a. Those having exact conformity with the standard definitions - [identical]

b. Those which are definitionally modified as per data availability or for contextual reasons- [similar]

c. Those which are used in the absence of quality data for the prescribed indicator[alternative]

d. Those not belonging to the above three categories and are left out either for reasons of contextual irrelevancy or for complete lack of data [invisible)

\section{Present structure and challenges-}

The present structure of statistical administration in India is multi-level and data is collected at the decentralized as well as centralized levels. All the core statistical activities in India are conducted by the nodal agency National Statistical Commission. The agency has the task of monitoring and coordinating all the major statistical activities that are conducted by different agencies. Ministry of Statistics and Programme Implementation (MOSPI) with its two arms Central Statistical Office (CSO) and National Sample Survey Organisation (NSSO) is the nodal ministry for collection, compilation, estimation and timely release of core statistics at the national level. At the sub national level, Directorate of Economics and Statistics is the nodal for collecting and organizing the data. Some key data sets generated for social indicators at national level are as follows:

- Health- Department of health and family welfare, Indian system of Medicines and Homeopathy (both under the Ministry of Health and Family Welfare), Registrar General of India through NHFS, SRS and Census are responsible for collecting data on health. National Population register would collect the biometric details of all Indian nationals.

- Education: Ministry of Human Resource Development collects vital information through State agencies on school education, while National Council of Education, Research and Training (NCERT) is responsible for collecting statistics on school education through All India Education Survey.

- Employment and Unemployment issues-NSSO under MOSPI contains large sample surveys to collect unemployment data in India. Besides this data on unemployment are also collected and provided by Registrar General of India 
through Census, Ministry of Labour and Employment, Labour Bureaus, and Employment Exchanges through Directorate General of Employment and Training.

- Consumption: NSSO conducts large sample surveys to collect data on the pattern and expenditure on consumption at the disaggregated levels separately for rural and urban areas across states and provides the basis for estimating poverty in the country. National Accounts Statistics (NAS) also provides consumption expenditure at the national level.

- Crime: National Crime Record Bureau (NCRB) compiles data and publishes crime statistics through various publications. Data on crime against women has been collected through National Family Health Survey (NFHS)-III and vital statistics on violence against women is captured in it.

- Gender and Child issues: The Census of India provides statistics on women on certain socio-demographic issues. Census, Sample Registration System, National Health Surveys, Education Surveys and socio-economic surveys conducted by NSSO provides useful information on child statistics.

- Green National Income Accounting: India's initiative on green GDP accounting is expected to be based on System Integrated Environmental and Economic Accounting (SEEA) developed by the United Nations Statistical Division in 1993, as a satellite system to its System of National Accounts (SNA), which is the international statistical standard. India plans to announce first round of "green" gross domestic product (GDP) data for India by around 2015. CSO and other agencies have started up with the calculation and valuation of green national income accounting.

\section{The Challenges}

The Indian Statistical System has evolved over the years but there have been still gaps in the information and absence of data for critical indicators such as women and child issues, extent of empowerment and contribution of women in GDP, key indicators of nutrition amongst children, crime against children etc are still missing. This brings to the forefront certain shortcomings that cripple the data collection system in India. The data collected at sub national level although is more economical and easier to collect and compile due to familiarity of local environment, however, they lack in timely reporting and quality. Another lacuna emerges in the methods of collecting data on consumer expenditures. The NAS provides estimates of national level data from national accounting framework. The estimates of Private Final Consumption Expenditure (PFCE) are computed following the "commodity flow" approach. The National Sample Survey Organisation (NSSO) conducts large sample surveys on households' consumption expenditure. The surveys cover only the households and not the consumption expenditure of private non-profit institutes serving households. The estimates of expenditure, thus, vary on account of approach or the methodology followed in arriving at these estimates. India estimates consumption poverty based on the consumption expenditure data collected by these agencies. The debate on the decline in the magnitude of poverty in the country gained momentum as the gap between the two estimates increased to almost 30 percent. This has invited severe criticism on the methodology followed in the country for estimating poverty using the NSS data on consumption expenditure.

MOSPI has conducted rounds of discussions of experts and set up working groups at regular intervals to address the issue of gaps in estimation of consumption expenditure. 
The latest working group set up by Central Statistical Organisation (CSO) has published its report in 20084. Some of the observations of the working group are reproduced below:

- The two data sets of private final consumption expenditure of NAS and NSS are not strictly comparable. Besides, there is difference in the concepts and methods of estimation followed by the two agencies.

- The major reasons for divergence between the two estimates are coverage, reference time frame, unmatched classification schemes, treatment of cooked meals, notional components in NAS estimates of PFCE (for instance, in NAS estimates of rent on dwellings, all imputed rentals of owner occupied dwellings while in NAS the rent actually paid is considered).

Finally, the major challenge in India lies ahead in mainstreaming of time use surveys which measures the tradeoff between work and leisure between men and women. Although these surveys can provide detailed information on how men and women distribute their time on activities and can capture a lot of useful information which might be difficult to be collected through other social, demographic and economic surveys, however, the methodology and certain policy deliberations are still to be decided keeping the infrastructure constraints and other limitations of the existing system before taking on these surveys.

In light of the above discussion, some broad inferences can be drawn.

- First, India recognizes the need of building a better statistical system for meeting the growing demands at the national and international levels.

- Second, there are certain data gaps in collection, coverage and dissemination of information critical for policy formulations requiring concerted efforts to overcome such gaps.

- Third, there is an urgent need to develop statistical system at the micro level to assess the impact of various policy interventions on the larger sections of society targeted through National and State level schemes and programmes.

- Fourth, major initiatives are required to capture some of the social indicators specifically related to women and child issues.

- Fifth, there is no clear indicator to measure the extent of social and political freedom in the country; hence, some proxy indicator needs to be developed.

- And, finally, there is scope for conducting surveys for aligning some subjective wellbeing indicators in the existing framework to measure the social progress in the country.

In the end, India has the opportunity to learn from the experiences of some of the countries who have tried to build up indices/indicators for on measuring the social

\footnotetext{
4 Report of the Group for Examining Discrepancy in PFCE estimates from NSSO Consumer Expenditure Data and estimates complied by National Accounts Division. See. http:// www.mospi.nic.in/mospi cso rept pubn.htm
} 
progress. In this context, a dashboard of indicators to begin with can be designed under monitorable targets with quantitative outcomes of the National Plans. Alternatively, National Human Development Report can be continued and improvements can be considered in developing a Human Development Index based on available indicators capturing the extent of development at the most disaggregated level possible. The feasibility of an exclusive large sample survey on measuring subjective well-being can be assessed as well.

\section{References:}

Alejandro Adler Braun (2009), "Gross National Happiness in Bhutan: A Living Example of an Alternative Approach to Progress", Wharton Research Scholars Journal, University of Pennsylvania Scholarly Commons.

Aggarwal, Yash (2003), 'Revitalisation of Educational Statistics in India- Issues and Strategies', National University of Educational Planning and Administration, New Delhi, Available at http:/ / www.dpepmis.org/ webpages.Edstatl.htm.

Baster, N., (1972), "Development Indicators: An Introduction”, in Baster,N. (eds) 'Measuring Development: The Role and Adequacy of Development Indicators', Frank Cass and company Ltd., London.

Becker, R. A., L. Denby, R.McGill and A. R.Wilks (1987), 'Analysis of data from the Places Rated Almanac', The American Statistician, August 1987, Volume 41, No. 3, pp. 169-186.

Central Statistical Organisation (2008), "Selected socio-economic statistics", Ministry of Statistics and Program Implementation, Government of India.

Challenges for Analysis of the Economy, the Businesses, and Social Progress', in Peter Kovacs et. al edited Abstract Book, Hungarian Central Statistical Office, Universitas Szeged Press, Szeged, 2009.

Dash, Jogeswar (2009), 'Social statistics in India: Challenges and New Initiatives', Central Statistical Organisation, Ministry of Statistics and Program Implementation, Government of India, Available at www.statssa.gov.za/ isi2009/ ScientificProgramme/ IPMS/ 0066.pdf.

Diener, Ed and Eunkook Suh (1997), 'Measuring Quality of Life: Economic, Social, and Subjective Indicators', Social Indicators Research, Kluwer Academic Publishers, Netherlands.

EESC (2009), 'GDP and beyond - Measuring progress in a changing world', Communication from the Commission to the Council and the European Parliament, Commission of European Committees, Brussels, 20 August 2009, Available at http://www.beyondgdp.eu/ .

EESC (2010), 'GDP and beyond - Measuring progress in a changing world', Opinion of the European Economic and Social Committee on the Communication from the Commission to the Council and the European Parliament, European Economic and Social Committee, Brussels, 29 April 2010, NAT/ SDO/ 453 - CESE 647/2010, Available at www.beyondgdp.eu/ download/ ces647-2010_ac_en.doc.

'Enhancing the Visibility and image of Statistical Agencies - Experience of India', Eighth Management Seminar for the Heads of NSO in Asia and the Pacific, 3-5 November, 2009, Central Statistical Organisation (CSO), Ministry of Statistics and Programme Implementation, Government of India, Available at www.unsiap.or.jp/ms/ms8/ p12_cc.ppt. 
Giovannini, Enrico, Jon Hall and Marco Mira d'Ercole (2008), 'Measuring Well-Being and Societal Progress', Organisation for Economic Co-operation and Development, Available at www.beyond-gdp.eu/ download/ oecd measuring-progress.pdf.

Goyal, Ashima (2007), 'Data and Definitions: Underestimating Savings and Investment in an Open Economy', Indira Gandhi Institute of Development Research, Mumbai, October 2007, Available at www.igidr.ac.in/ pdf/ publication/WP-2007-015.pdf.

Gruen, David and Joann Wilkie (2009), New paradigms to measure progress', 3rd OECD World Forum on Statistics, Knowledge and Policy, Busan, on 28 October 2009.

Heylighen F. \& Bernheim J. (2001), "Measuring Global Progress Through Subjective WellBeing", in: Proceedings of the III Conference of the ISQOLS, University of Girona Press.

Hicks,N.and Streeten, P. (1979), "Indicators of Development: The Search for a Basic Needs Yardstick", World Development, vol.7, no.6 (p.567-580).

Hoegen, Monika (2009), 'Statistics and the quality of life: Measuring progress - a world beyond GDP", InWEnt Centre for Economic, Environmental and Social Statistics, Invent Capacity Building International, on behalf of Federal Ministry of Cooperation and Development, Germany.

Millennium Development Goals, India Country Report 2007, Central Statistical Organization, Ministry of Statistics and Programme Implementation, Government of India, http:// www.mospi.nic.in

Mira, Marco d'Ercole (2009), 'Alternative models of measuring progress', ETUI Conference on Beyond the crisis: Developing sustainable alternatives, Brussels, 10 - 11 September 2009.

New Economic Foundation (2009), "Happy Planet Index 2.0" The reports available at: http:/ / www.happyplanetindex.org/ public-data/ files/ happy-planet-index-2-0.pdf.

Osberg, Lars (2001), 'Needs and Wants: What is Social Progress and how should it be measured?', The Review of Economic Performance and Social Progress, Edited by Keith Banting, Andrew Sharpe and France St-Hilaire, Volume 1, June 2001.

Pesendorfer, Konrad (2010), 'Measuring Progress of Societies in Official Statistics', United Nations, Vienna 14 October 2010.

Planning Commission (2013), "Twelfth Five year plan: Faster, More Inclusive and Sustainable Growth", Vol-I \& II, Government of India.

Planning Commission (2011), "Measuring Progress in the Society-India Country Paper", presented in the $15^{\text {th }}$ Conference of Commonwealth Statisticians at New Delhi, 7-10 February.

Radermacher, Walter (2010), a Keynote Speech on Measuring prosperity and quality of life, Austrian Federal Ministry of Finance in Vienna, May 2010.

Rawls, J. (1971), 'A Theory of J ustice', Cambridge, MA, Harvard University Press.

Report of The Group for Examining Discrepancy in PFCE Estimates from NSSO Consumer Expenditure Data and Estimates Compiled by National Accounts Division, Central Statistical Organisation, Ministry of Statistics \& Programme Implementation, Government of India, January 2008.

Rust, Christa (2009), 'Measuring Progress, Strengthening Governance and Promoting Positive Change- Developing sustainability indicators with Winnipeg's urban First Nations community', International Institute for Sustainable Development, Canada, January 2009.

Schreiner, Mark (2008), 'Progress out of Poverty Index- A Simple Poverty Scorecard for India', Grameen Foundation, July 7, 2008. 
Sen, A. K. (1989), 'Development as Capability Expansion', Journal of Development Planning, Vol. 19, pp 41-58, reprinted in S. Fukuda-Parr and A. K. Shiva Kumar (eds) (2003) Readings in Human Development, Oxford University Press, Oxford.

Sen, A.K., Joseph, E. Stiglitz and Fitaussi Paul (2009), Report of the Commission on the Measurement of Economic Performance and Social Progress. See. http:// www.stiglitz-senfitoussi.fr/ documents/rapport anglais.pdf

Sojo, Eduardo and Inegi Mexico (2009), 'Challenges for the Implementation of Better Indicators of Social Progress', The 3rd OECD World Forum on Statistics, Knowledge and Policy, 27-30 October, 2009.

Stern, Scott; Amy Wares and Sarah Orzell (2015), "Social Progress Index 2015 Methodological Report", Social Progress Imperative, USA.

United Nations (2001), 'Road map towards the implementation of the United Nations

Millennium Declaration', Report of the Secretary-General, Fifty-sixth session, General Assembly, 6 September 2001. See.

http:// unpan1.un.org/intradoc/groups/ public/ documents/ un/ unpan004152.pdf

United Nations (2002), 'Statistical system in India', United Nations Economic and Social Commission for Asia and The Pacific, Bangkok, 9-11 October 2002.

United Nations (2003), 'Indicators for Monitoring the Millennium Development GoalsDefinitions, Rationale, Concepts and Sources', Department of Economic and Social AffairsStatistics Division, ST/ ESA/ STAT/ SER.F/ 95, United Nations Publication, New York.

United Nations (2006), 'Statistical Challenges in Assessing the Achievement of the Millennium Development Goals and Other Internationally Agreed Development Goals', Committee on Poverty Reduction, Economic and Social Commission for Asia and The Pacific, United Nations Economic and Social Council, Third Session, 20 October 2006. See http:// www.unescap.org/pdd/CPR/ CPR2006/ English/CPR3_3E.pdf

United Nations (2010), 'Historical Perspective of Official Statistics in India', United Nations Statistics Division, United Nations, New York

United Nations Development Programme (2010), "Human Development Report 2010- 20th Anniversary Edition- The Real Wealth of Nations: Pathways to Human Development"

Journal RGE Website: http:/ / www.usc.es/ econo/ RGE/ benvidag.htm 